Provided for non-commercial research and education use. Not for reproduction, distribution or commercial use.

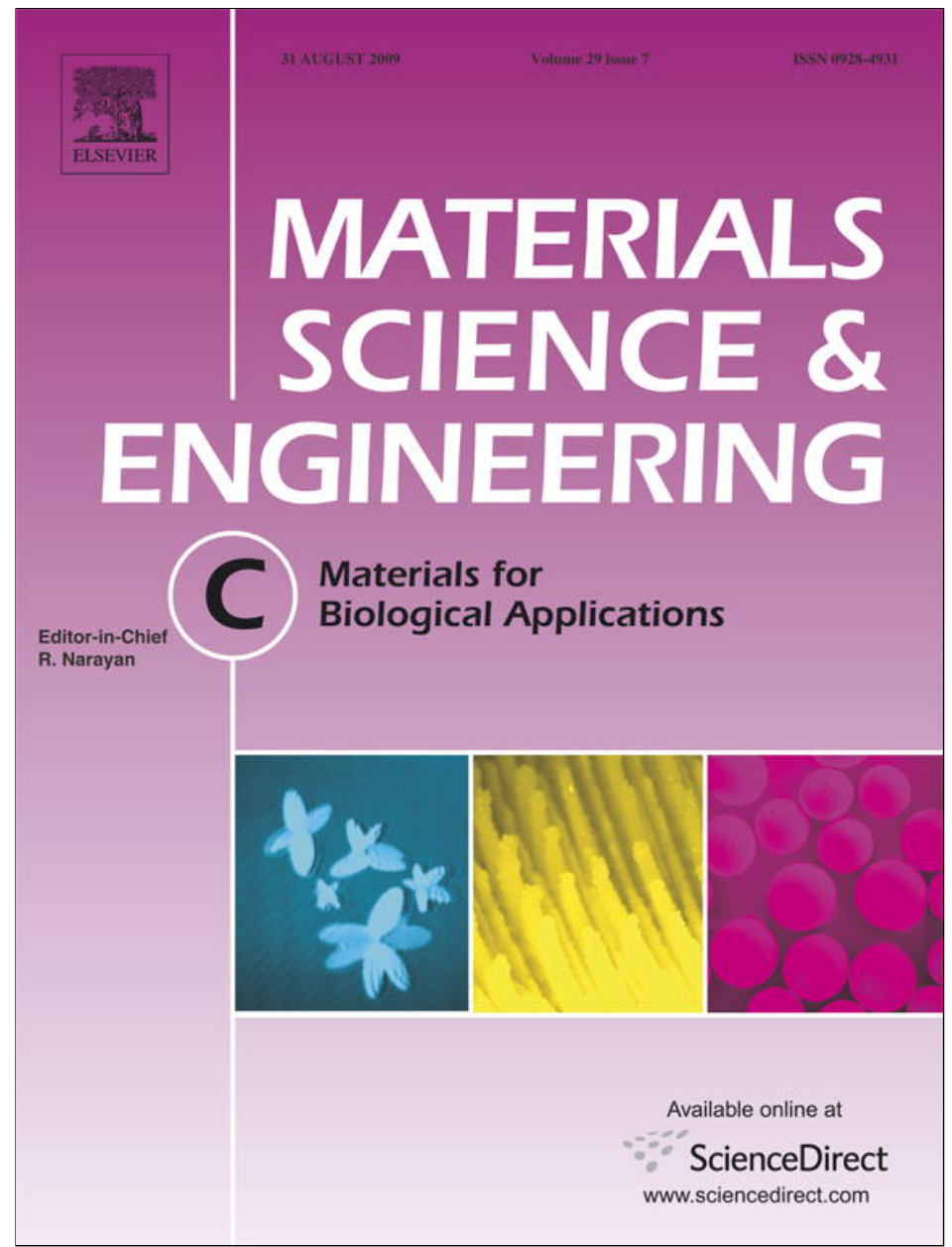

This article appeared in a journal published by Elsevier. The attached copy is furnished to the author for internal non-commercial research and education use, including for instruction at the authors institution and sharing with colleagues.

Other uses, including reproduction and distribution, or selling or licensing copies, or posting to personal, institutional or third party websites are prohibited.

In most cases authors are permitted to post their version of the article (e.g. in Word or Tex form) to their personal website or institutional repository. Authors requiring further information regarding Elsevier's archiving and manuscript policies are encouraged to visit:

http://www.elsevier.com/copyright 


\title{
Processing of novel bioactive polymeric matrixes for tissue engineering using supercritical fluid technology
}

\author{
Ana Rita C. Duarte ${ }^{\mathrm{a}, \mathrm{b}, *}$, Sofia G. Caridade ${ }^{\mathrm{a}, \mathrm{b}}$, João F. Mano ${ }^{\mathrm{a}, \mathrm{b}}$, Rui L. Reis ${ }^{\mathrm{a}, \mathrm{b}}$ \\ a 3 B's Research Group, Biomaterials, Biodegradables and Biomimetics, University of Minho, Headquarters of the European Institute of Excellence on Tissue Engineering and Regenerative \\ Medicine, AvePark, 4806-909 Taipas, Guimarães, Portugal \\ ${ }^{\mathrm{b}}$ IBB, Institute for Biotechnology and Bioengineering, PT Government Associated Laboratory, Guimarães, Portugal
}

\section{A R T I C L E I N F O}

\section{Article history:}

Received 14 January 2009

Accepted 14 April 2009

Available online 19 April 2009

\section{Keywords:}

Supercritical fluids

PLLA

Bioglass ${ }^{\circledR}$

Phase inversion

Natural polymers

Tissue engineering

\begin{abstract}
A B S T R A C T
The aim of this study was to develop a new process for the production of bioactive 3D scaffolds using a clean and environmentally friendly technology. The possibility of preparing composite scaffolds of Bioglass ${ }^{\circledR}$ and a polymeric blend of starch and poly(L-lactic acid) (SPLA50) was evaluated. Supercritical phase-inversion technique was used to prepare inorganic particles loaded starch-based porous composite matrixes in a onestep process for bone tissue engineering purposes.

Due to their osteoconductive properties some glasses and ceramics are interesting materials to be used for bone tissue engineering purposes; however their poor mechanical properties create the need of a polymeric support where the inorganic fraction can be dispersed. Samples impregnated with different concentrations of Bioglass ${ }^{\circledR}$ (10 and $15 \%$ wt/wt polymer) were prepared at 200 bar and $55^{\circ} \mathrm{C}$. The presence of Bioglass ${ }^{\circledR}$ did not affect the porosity or interconnectivity of the polymeric matrixes. Dynamic mechanical analysis has proven that the modulus of the SPLA50 scaffolds increases when glass particles are impregnated within the matrix. In vitro bioactivity studies were carried out using simulated body fluid and the results show that a calciumphosphate layer started to be formed after only 1 day of immersion. Chemical analysis of the apatite layer formed on the surface of the scaffold was performed by different techniques, namely EDS and FTIR spectroscopy and X-ray diffraction (XRD). The ion concentration in the simulated body fluid was also carried out by ICP analysis. Results suggest that a bone-like apatite layer was formed.

This study reports the feasibility of using supercritical fluid technology to process, in one step, a porous matrix loaded with a bioactive material for tissue engineering purposes.
\end{abstract}

(c) 2009 Elsevier B.V. All rights reserved.

\section{Introduction}

Understanding the biological mechanisms behind the processes of regeneration of the living tissues may help the development of nature-inspired materials designed and tailored to mimic the natural systems. Thus the definition of tissue engineering has been changing over the past several years from a material that functioned only as an inert structural support for cell attachment to serving as a more complex and dynamic environment for tissue development $[1,2]$.

A wide variety of materials have been used for the preparation of scaffolds from metals to ceramics and polymers. Natural polymers have unique, intrinsic properties that make them appealing to be used in scaffolding, [3] namely the fact that they are in general non-toxic, even in large concentrations, mucoadhesive, biocompatible, and biodegradable [4,5]. However, they do not present inherent bioactivity. On the other hand, some ceramics and glasses exhibit osteoconductive

\footnotetext{
* Corresponding author. IBB, Institute for Biotechnology and Bioengineering, PT Government Associated Laboratory, Guimarães, Portugal. Tel.: +351 253 510900; fax: +351253510909.

E-mail address: aduarte@dep.uminho.pt (A.R.C. Duarte).
}

properties. The major drawback of these materials is the fact that they present poor mechanical properties and a very slow degradability, which does not appear to be very attractive for tissue engineering [6]. Nonetheless, a vast number of manufacturing techniques have been employed in the last years to manufacture three dimensional ceramic scaffolds, with the intention to replicate the architecture of native bone as well as to repair and restore bone function [7].

To overcome the lack of bioactivity of the polymers and the poor mechanical properties of the ceramics, the preparation of composite matrixes of these two materials is regarded as an interesting approach. Biodegradable composites containing hydroxyapatitebased calcium phosphates (CaP) $[8,9]$ and Bioglass ${ }^{\circledR}[10]$ can be used to produce promising scaffolds for bone tissue engineering.

A method to evaluate the bioactivity of the materials using simulated body fluid (SBF) was developed by Kokubo et al. [11,12]. In their studies they conclude that an essential requirement for a scaffold to bond to living bone is the formation of bone-like apatite on its surface. This can be mimicked in a simulated body fluid with ion concentrations close to those of human blood plasma [13]. According to this, the in vivo bone bioactivity of a material can be predicted from the apatite formation on its surface upon immersion in SBF. The main characteristic of this 
method is that the apatite layer obtained consists of bone-like apatite, more similar to natural bone with a low crystallinity and nano-crystal size. The creation of the layer occurs out in SBF, under mild conditions in which, the ion concentrations, temperature and $\mathrm{pH}$ of are adjusted to almost equal to those of human blood plasma. Our group has reported the successful preparation of different composite matrixes from naturalbased polymers with ceramics, using different techniques [14-17].

One of the most important stages of tissue engineering is the design and processing of a porous 3D structure, with high porosity, high interconnectivity between the porous and uniform distribution. Techniques using supercritical fluids may be used in the processing of structures for tissue engineering applications [18]. In particular, the supercritical assisted phase-inversion method has shown to be feasible for the preparation of polymer scaffolds with high porosity and interconnected pores [19]. The phase-inversion method involves casting of a polymer solution onto an inert support followed by immersion of the support with the cast film into a bath filled with a non-solvent for the polymer. The contact between the solvent and the non-solvent causes the solution to be phase-separated. Several advantages exist if the nonsolvent used is a supercritical fluid. An important advantage of the use of carbon dioxide is the fact that simply by tuning the processing conditions, i.e. pressure and temperature, one can tailor the final structure of the product. Additionally, when carbon dioxide is used as a non-solvent a subsequent drying step is avoided and the porous structure obtained is a dry product free of any residual solvent.

Carbon dioxide is the most commonly used supercritical fluid as it has mild critical parameters, it is environmentally benign, non-toxic, non-flammable, non-corrosive, ready available and inexpensive. Its elimination and the recovery of final products are easier (no residue is left and a dry solid product is easily obtained, just by controlling the pressure), leading to processes with less energy consumption [20].

The use of carbon dioxide as a non-solvent for phase separation has been successfully reported in the literature for several synthetic polymers [21-26]. Recently we have proposed the use of this technique for the preparation of scaffolds from natural sources [27]. A starch-based blend (SPLA50) was successfully processed by supercritical assisted phase-inversion method. Starch-based polymers have been purposed for a wide range of bone-related therapy applications, such as tissue engineering scaffolds [28-30] or bone cements [31,32]. The natural origin, together with interesting mechanical properties and biocompatibility supports the potential of starch-based materials in the biomedical field.

To our knowledge the use of supercritical phase-inversion technique for the preparation of composite matrixes of a polymer and a ceramic material, for tissue engineering purposes, is for the first time reported in this work. In this study, the possibility of preparing in a one-step process a porous matrix loaded with a bioactive agent is evaluated. This methodology could open other possibilities of developing substrates for tissue engineering or biomedical applications, where processing of biomaterials and incorporation of bioactive agents are combined using supercritical fluid technologies.

\section{Experimental procedure}

\subsection{Materials}

A commercial blend of starch and poly-L-lactic acid containing $50 \mathrm{wt} . \%$ of both components (SPLA50) was obtained from Novamont. Bioglass ${ }^{\circledR} 45 \mathrm{~S} 5$ (BG) micro-particles with a composition of $45 \% \mathrm{SiO}_{2}$, $24.5 \% \mathrm{CaO}, 24.5 \% \mathrm{Na}_{2} \mathrm{O}$ and $6 \% \mathrm{P}_{2} \mathrm{O}_{5}$ was supplied by US Biomaterials Corp. Chloroform, (CAS 67-68-5, 99.9\% purity) was purchased from Vaz Pereira. Carbon dioxide, (99.998 mol\%) was supplied by Air Liquide. All chemicals were used with no further purification.

\subsection{Supercritical assisted phase-inversion process}

The phase-inversion experiments were carried out as described in a previous work. ${ }^{19}$ SPLA50 was mixed with Bioglass $®$ glass and dissolved in chloroform. This procedure was performed separately for each of the ratios of BG and polymer analysed: 10 or $15 \% \mathrm{wt} / \mathrm{wt}$ (Bioglass $\AA$ : polymer). In each experiment ca. $2 \mathrm{ml}$ of the polymer solution was loaded in a stainless steel cap with $2 \mathrm{~cm}$ diameter, which was placed inside the high pressure vessel. The vessel was heated in by means of an electric thin band heater (OGDEN) connected to a temperature controller, that maintained temperature within $\pm 1{ }^{\circ} \mathrm{C}$ (TC). Carbon dioxide was pumped into the vessel using high pressure piston pump (P-200A Thar Technologies) until the operational pressure was attained. The pressure inside the vessel was measured with a pressure transducer (P). The system was closed for $45 \mathrm{~min}$ to allow the occurrence of phase separation. Afterwards the system was flushed for another $45 \mathrm{~min}$, with a stream of carbon dioxide at very low flow rate $(5 \mathrm{~g} / \mathrm{min})$, in order to ensure complete drying of the membranes. The flow was regulated by a flow meter (FM - Siemens, SITRANS FC MASS FLO MASS2100). The outflow was regulated by a back pressure valve (Go, Inc, USA).

\subsection{Dynamic mechanical analysis (DMA)}

The viscoelastic measurements were performed using a TRITEC8000B DMA from Triton Technology (UK), equipped with the

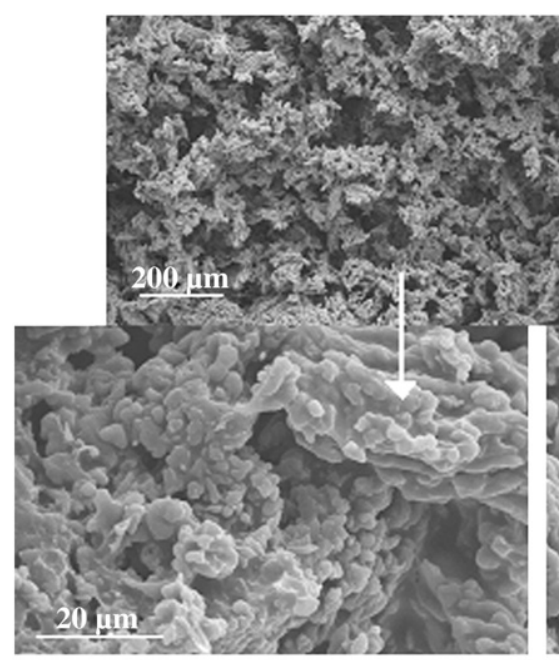

SPLA50

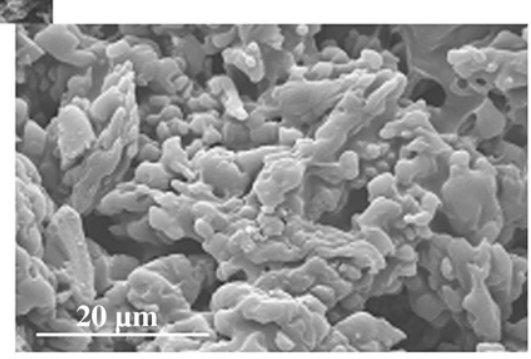

SPLA50: BG $10 \mathrm{wt} \%$

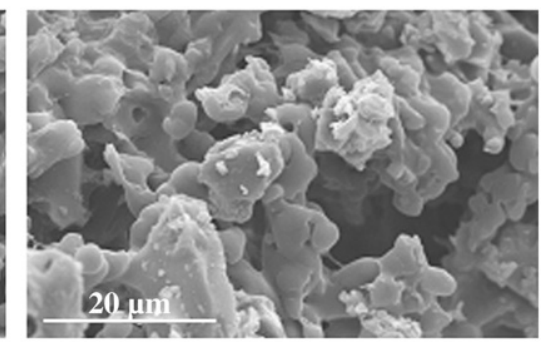

SPLA50: BG $15 \mathrm{wt} \%$

Fig. 1. SEM images of cross-sections of the polymer samples prepared from a polymer solution with 15 wt. $\%$ at 200 bar, $55^{\circ} \mathrm{C}$. 


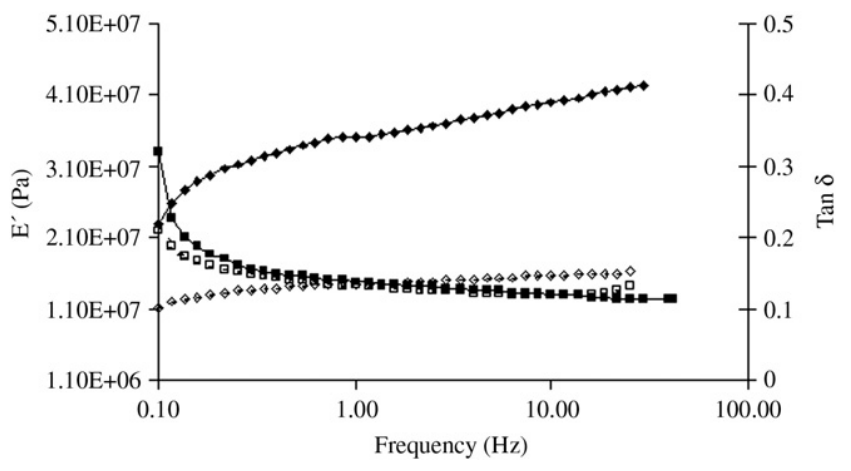

Fig. 2. Storage modulus $\left(E^{\prime}\right)(\diamond, \diamond)$ and loss factor $(\tan \delta)(\mathbf{\square}, \square)$ versus log frequency (solid symbols: SPLA50:BG 15 wt.\% and open symbols: SPLA50) obtained at room temperature.

compressive mode. The measurements were carried out at room temperature. Samples were cut in cylindrical shapes with about $5 \mathrm{~mm}$ diameter and $2 \mathrm{~mm}$ thickness. The geometry of the samples was then measured and the samples were clamped in the DMA apparatus. After, the DMA spectra were obtained during a frequency scan between 0.1 and $50 \mathrm{~Hz}$. The experiments were performed under constant strain amplitude $(30 \mu \mathrm{m})$. The results presented are the average of at least 3 measurements with a standard deviation error $<9 \%$.

\subsection{In vitro bioactivity experiments}

Standard bioactivity tests were performed [33]. Samples were immersed in Simulated Body Fluid (SBF) at $37^{\circ} \mathrm{C}$ and $\mathrm{pH}=7.45$ during $0,1,3,7$ and 14 days. The SBF has a composition similar to the human blood plasma and has been reported several times for use in in vitro bioactivity tests. After immersion samples were immediately cleaned with distilled water and dried.

\subsection{Surface analysis}

\subsubsection{Scanning Electron Microscopy - SEM}

Samples of the polymeric matrixes prepared were observed by a Leica Cambridge S360 Scanning Electron Microscope. The matrixes were fixed by mutual conductive adhesive tape on aluminium stubs and covered with gold palladium using a sputter coater. After immersion in SBF the samples were again analysed in order to check the appearance of a calcium-phosphate layer on the surface of the matrixes.

\subsubsection{Fourier Transformed Infra Red analysis}

FTIR analysis was used to demonstrate the formation of an apatite layer on the surface of the structures. Spectra were recorded at 32 scans with a resolution of $2 \mathrm{~cm}^{-1}$ (Shimadzu - IR Prestige 21).

\subsubsection{X-ray diffraction analysis}

Thin-film X-ray diffraction (TF-XRD, Philips X'Pert MPD) was used to characterize the crystalline/amorphous nature of the films and to identify any crystalline phases present after immersion in SBF (results were compared to non-immersed controls). The data collection was performed by $2 q$ scan method with $1^{\circ}$ as incident beam angle using CuKa X-ray line and a scan speed of $0.05^{\circ} / \mathrm{min}$ in $2 q$.

\subsection{Solution analysis}

The evolution of $\mathrm{Ca}$ and $\mathrm{P}$ ion concentrations of the SBF solutions was determined as a function of the immersion time. The ion concentrations were measured by inductively coupled plasma emission (ICP) spectroscopy (ICP-OES, JY 70 plus, Jobin Yvon).

\section{Results and discussion}

\subsection{Synthesis of SPLA50 and Bioglass ${ }^{\circledR}$ (BG) loaded SPLA50 scaffolds}

This study intends to evaluate the possibility of preparing Bioglass $®$-loaded SPLA50 scaffolds with potential application in tissue engineering using supercritical fluid technology. Scaffolds with two different BG concentrations were prepared, namely 10 and $15 \% \mathrm{wt} / \mathrm{wt}$ (BG:polymer). Samples were prepared at $55^{\circ} \mathrm{C}$ and 200 bar and the morphology of the matrixes was evaluated by SEM analysis (Fig. 1).

The synthesis of SPLA50 scaffolds loaded with bioglass leads to structures with similar morphologies to the unloaded scaffolds. Therefore, the impregnation of bioglass does not seem to produce significant changes in the morphology of the polymeric structures. The SPLA50 matrixes obtained by supercritical assisted phase inversion are bicontinuous structures characterized by a rough surface where micro and macropores are visible. Such particular microstructure enhances the transport properties within the structure and could

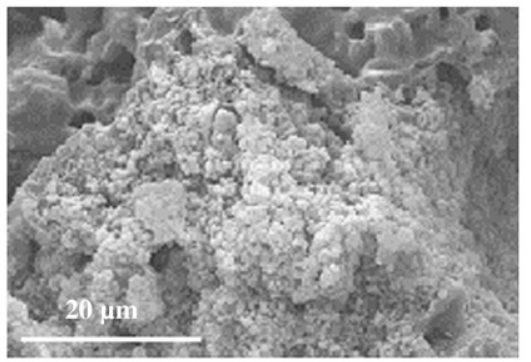

1 day

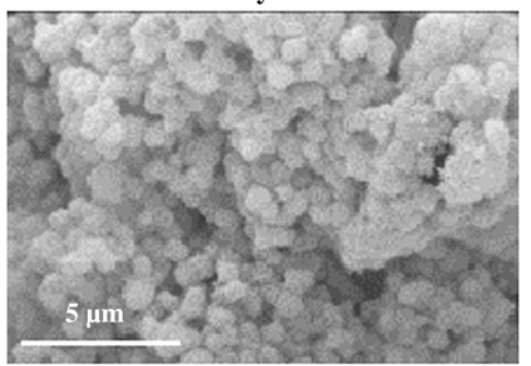

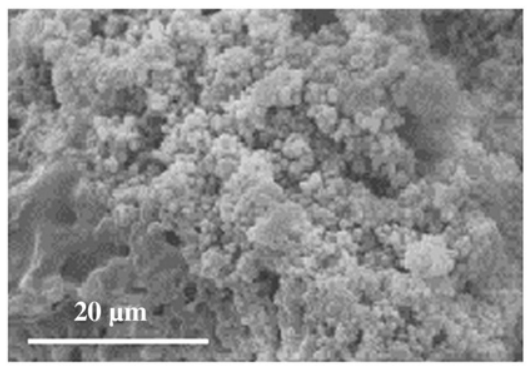

7 days

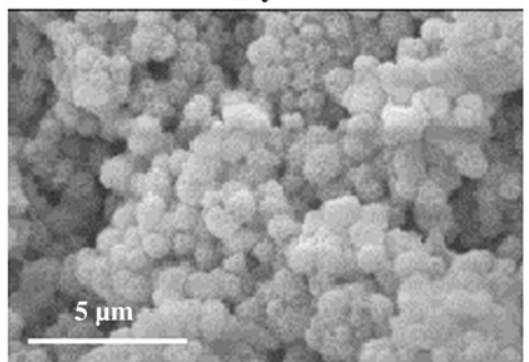

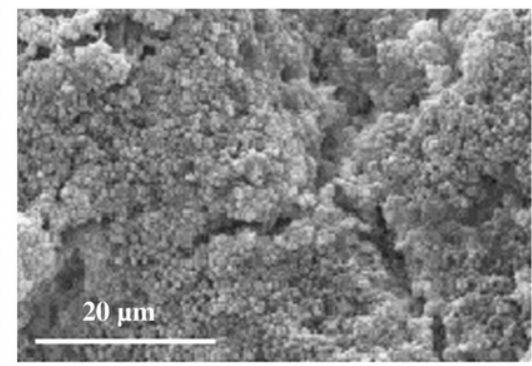

14 days

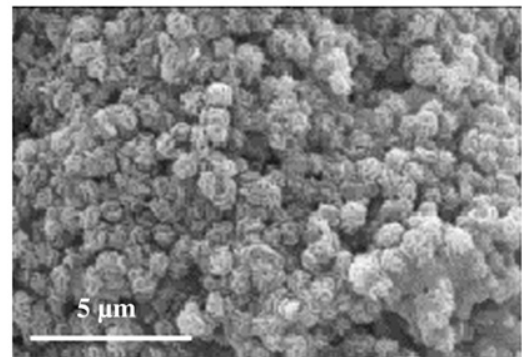

Fig. 3. SEM images of cross-sections of the samples of SPLA50:BG 10 wt.\% immersed for different periods in SBF solution. 


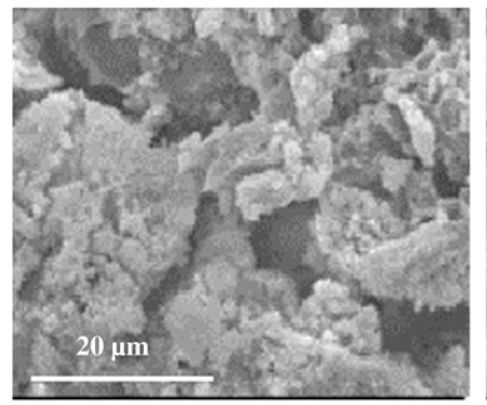

1 day

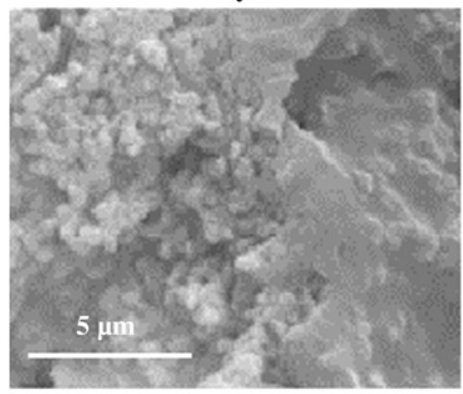

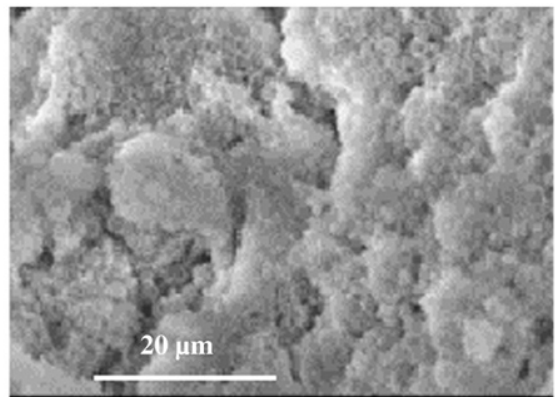

7 days

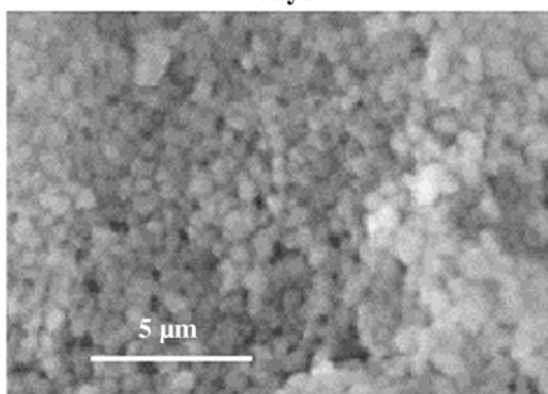

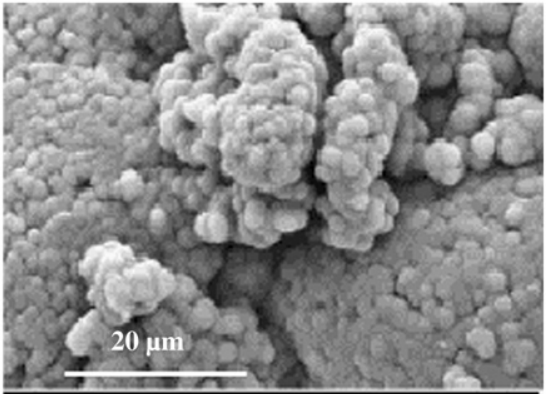

14 days

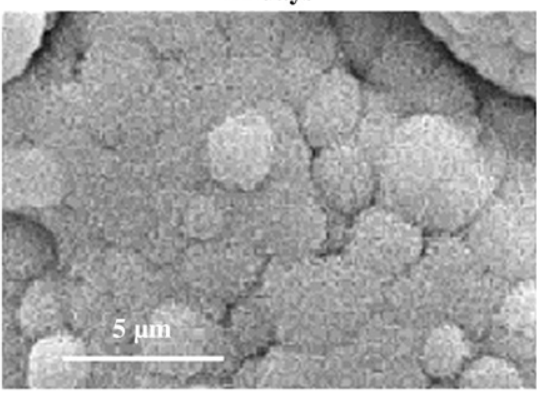

Fig. 4. SEM images of cross-sections of the samples of SPLA50:BG 15 wt.\% immersed for different periods in SBF solution.

also encourage cell attachment and proliferation. The matrixes are also characterized by a highly interconnected porous structure.

Nonetheless similar morphologies that obtained the mechanical properties of the scaffolds vary when adding Bioglass ${ }^{\circledR}$ to the blend. $E^{\prime}$ and $E^{\prime \prime}$, the storage and the loss modulus, respectively, were measured using dynamic mechanical analysis (DMA). $E^{\prime}$ (the elastic component) is related with the stiffness of the material, while $E^{\prime \prime}$ (the viscous component) is associated with the dissipation of energy, as heat, due to internal friction at the molecular level. The loss factor, $\tan \delta$, is defined as the ratio $E^{\prime \prime} / E^{\prime}$.

Fig. 2 shows the isothermal DMA response of the various samples as a function of frequency in terms of storage modulus $\left(E^{\prime}\right)$, and loss factor $(\tan \delta)$, respectively. It was observed that an increase in the storage modulus was obtained when BG particles are present. This would be expected as the bioglass particles reinforced the scaffolds.

A similar trend for SPLA50 and SPLA50:BG was observed for $\tan \delta$. This indicates that the scaffolds reinforced with bioglass will have similar damping characteristics of the pure SPLA50 scaffolds.

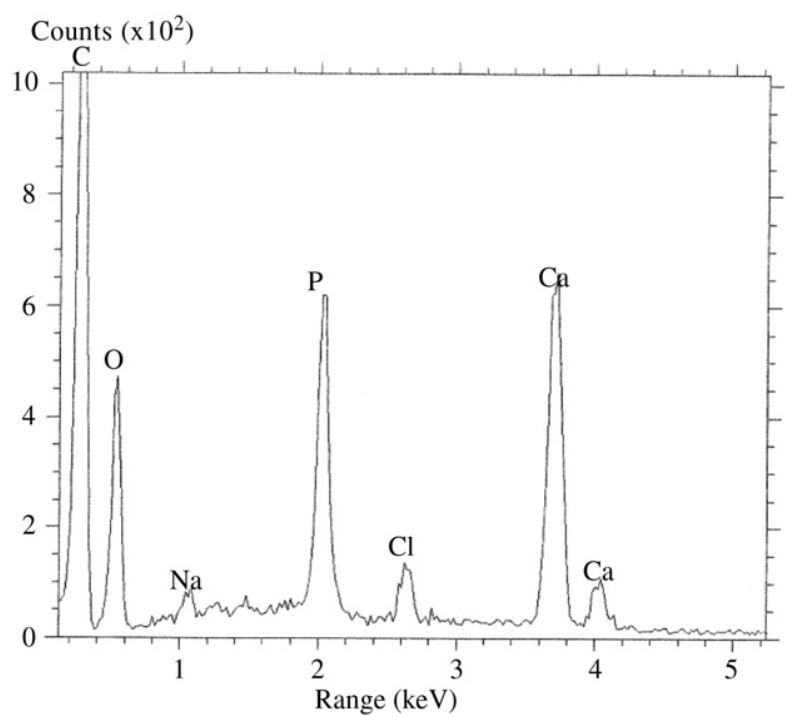

\subsection{Bioactivity evaluation - surface analysis}

The bioactive character of the SPLA50-based scaffolds produced was tested in vitro by analysing the apatite formation at the material surface after exposure to SBF. SEM micrographs of the immersed scaffolds of SPLA50:BG 10 and 15 wt.\% are shown in Figs. 3 and 4, respectively. Two different magnifications are shown.

Besides changing the mechanical properties of the scaffold, the dispersion of BG in the polymer matrix promotes the formation of an apatite like coating in contact with SBF. In the lower magnification SEM images we can have an idea of the extension of the calciumphosphate layer formed. Immediately after one day of immersion it is possible to observe a CaP layer that starts to be formed around the BG particles dispersed in the polymeric matrix. The formation of the apatite layer occurs on the surroundings of Bioglass ${ }^{\circledR}$ particles hence, it is important that glass particles are exposed to the fluid environment at various stages during in vitro degradation of the composite. The high porosity and interconnectivity of the SPLA50

Counts $\left(\times 10^{3}\right)$

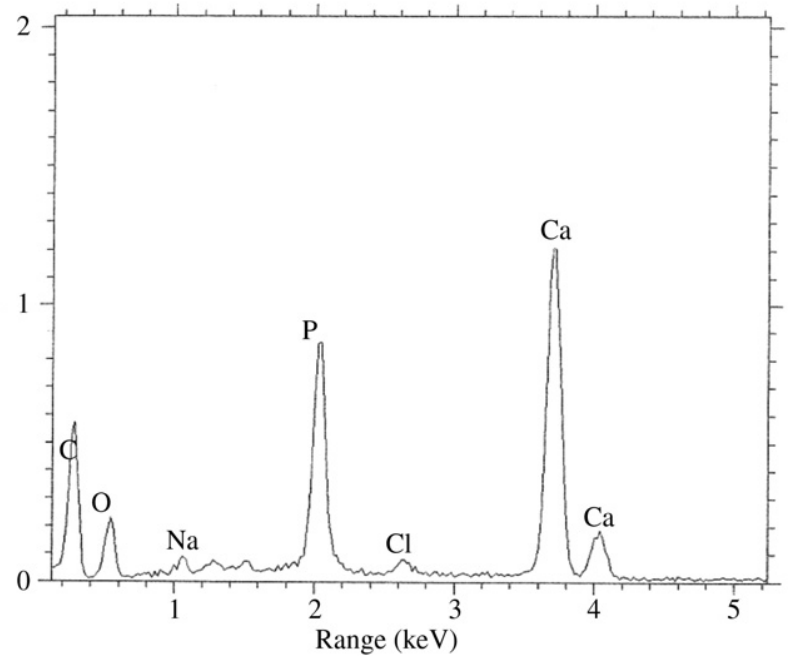

Fig. 5. EDS spectra of the scaffolds immersed for 14 days (left: SPLA50:BG $10 \mathrm{wt. \%}$ and right: SPLA50:BG $15 \mathrm{wt} . \%$ ). 


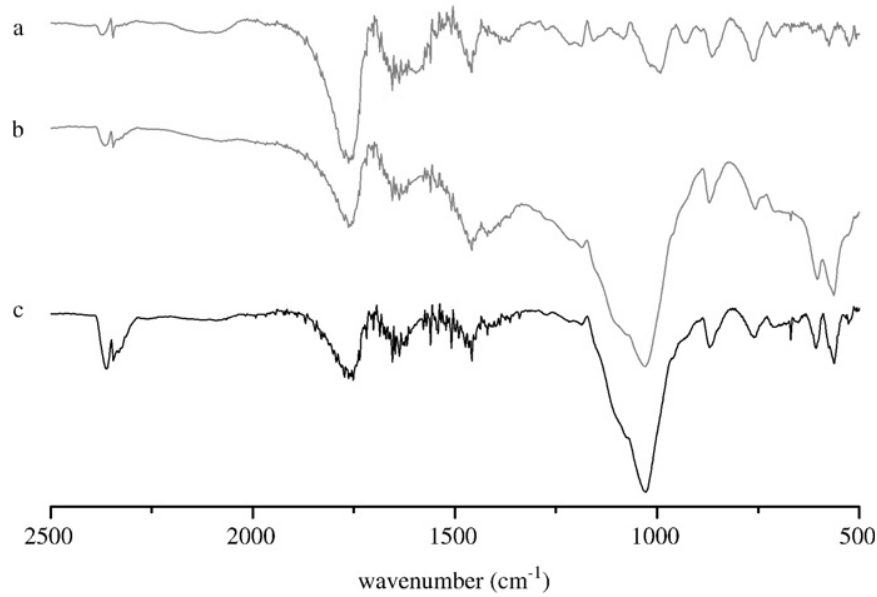

Fig. 6. FTIR spectra of the scaffolds a) SPLA50; b) SPLA50:BG 10 wt.\% immersed for 14 days and c) SPLA50:BG 15 wt.\% immersed for 14 days.

scaffolds prepared by supercritical fluid assisted phase inversion guarantees that the fluid is able to penetrate the matrix. Studies on the swelling degree of this polymeric matrix, reported in a previous paper, ${ }^{27}$ give an indication on the water uptake capability of the SPLA50 scaffold which is $290 \%$ after 7 days of immersion. Water uptake will also help in the dissolution of the ions from the BG particles that will induce the CaP deposition, enhancing the calcification process of the matrix upon immersion in SBF.

After seven days of immersion in SBF the SPLA50:BG samples prepared with 15 wt.\% BG have a denser film of CaP than the scaffold prepared with $10 \mathrm{wt} . \%$ BG. Finally, after 14 days the sample containing a higher concentration of $\mathrm{BG}$ has a compact layer of $\mathrm{CaP}$ formed on the surface of the pores. At higher magnification, it is possible to distinguish the typical cauliflower morphology of bone-like apatite layer where needle like crystals are agglomerated. It is important to note that even for the conditions more favourable for the deposition of apatite, the ceramic fraction did not compromise the interconnectivity of the scaffolds (see SEM images with lower magnification). This is an important aspect, as one must warrant the transfer of nutrients to the cells and to remove the wastes from the cells, maintaining at the same time the ability of cell to migrate.

The morphological analysis combined with the energy dispersive spectroscopy (EDS) analysis confirms the presence of a CaP layer (Fig. 5).

The analysis of the EDS spectra of the coated samples indicates that indeed the ionic composition of the layer consists mainly on Ca and P. Although no quantitative data can be taken from the EDS spectra obtained we can conclude from the relative intensity of the $\mathrm{Ca}$ and $\mathrm{P}$ peaks that a thicker layer of CaP is formed when $15 \mathrm{wt} . \%$ of $\mathrm{BG}$ is impregnated in the polymer matrix.

The CaP layer was further characterized by Fourrier Transformed Infra Red (FTIR) spectroscopy. Fig. 6 presents an example of the nonimmersed sample and two composite samples after immersion for 14 days.

After CaP deposition the characteristic band of the $\mathrm{P}-\mathrm{O}$ stretching appears. The spectrum exhibits the characteristic peak of the phosphate in the region $1190-1020 \mathrm{~cm}^{-1}$ ( $\nu_{3}$ band) and two other peaks at $606 \mathrm{~cm}^{-1}$ and $565 \mathrm{~cm}^{-1}$ ( $v_{4}$ band). Regarding the absorption peak of the carbonate groups it was also detected at $878 \mathrm{~cm}^{-1}$ ( $v_{2}$ band).

The XRD pattern of the scaffolds immersed in SBF for the different time periods is shown in Fig. 7.1 and 7.2.

The formation of a partially crystalline HA layer was confirmed by XRD analysis. In addition to the diffraction peaks at $2 \theta=16.7^{\circ}$ and $19.2^{\circ}$, which are characteristic of the polymer matrix (PLLA), the main diffraction peak characteristic of hydroxyapatite, at $2 \theta=32^{\circ}$ (contribution of the (211), (112) and (300) planes of apatite) can be observed. This peak appears immediately after one day of immersion and becomes more intense for longer immersion periods as a denser layer of HA is formed. The peak $2 \theta=22.9^{\circ}$ ((111) diffraction peak) is also characteristic of the CaP layer formed. The intensity of this peak, which should be $10 \%$ of the (211), indicates that a partially crystalline structure is formed. The results obtained by both FTIR and XRD allow us to conclude that the CaP formed upon immersion in SBF exhibits the typical features of the carbonated apatite found in bone.

\subsection{Bioactivity evaluation - solution analysis}

Fig. 8 shows the results of the induced-coupled plasma emission (ICP) spectroscopy. The ion concentration ( $\mathrm{Ca}$ and $\mathrm{P}$ ) in the SFB solution is represented as a function of immersion time. The control represents the measurements of the SBF solution and the SPLA50 sample refers to a non-impregnated scaffold.

For both calcium and phosphate the concentration in solution decreases with increasing time exposure for the samples synthesized with 10 and 15 wt.\% BG. This behaviour indicates that calcium and phosphorous are being deposited at the surface of the scaffold. Regarding the SPLA50 scaffold and for all the immersion periods no changes in the ion concentration were observed indicating that there was no uptake of either Ca or P. These samples could not in any case induce the formation of an apatite layer, as these materials are non-
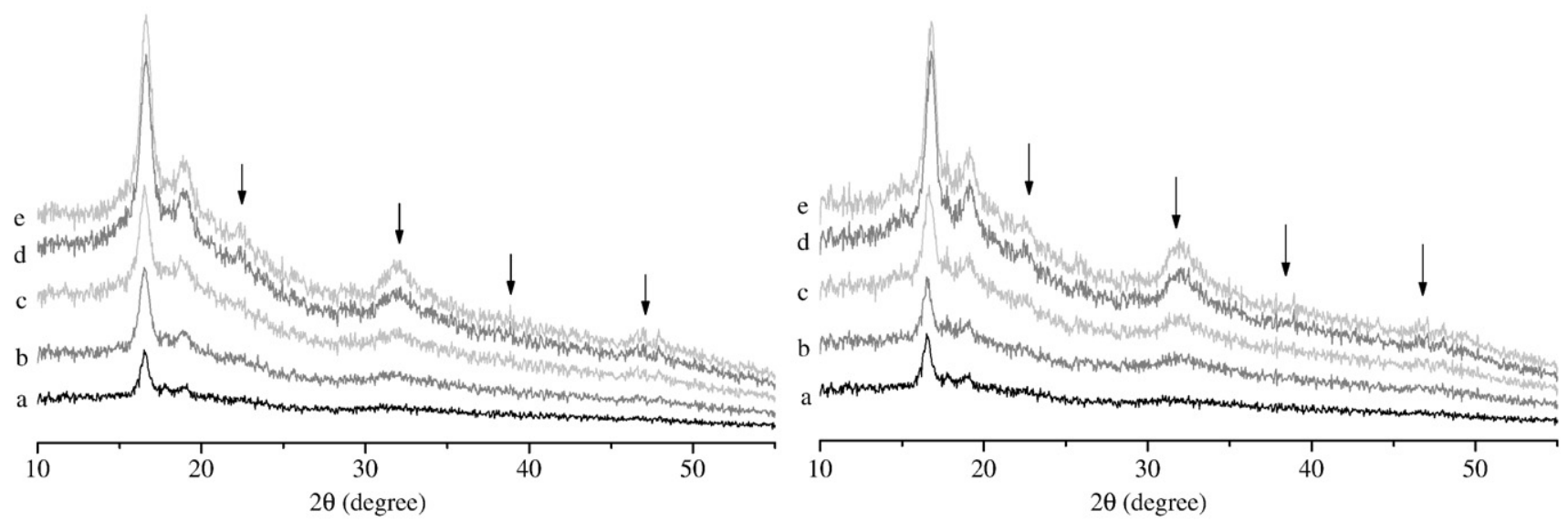

Fig. 7.1. XRD spectra of the scaffold SPLA50:BG 10 wt.\% immersed for a) 0 days; b) 1 day; c) 3 days; d) 7 days and e) 14 days. Fig. 7.2 XRD spectra of the scaffold SPLA50:BG 15 wt.\% immersed for a) 0 days; b) 1 day; c) 3 days; d) 7 days and e) 14 days. 

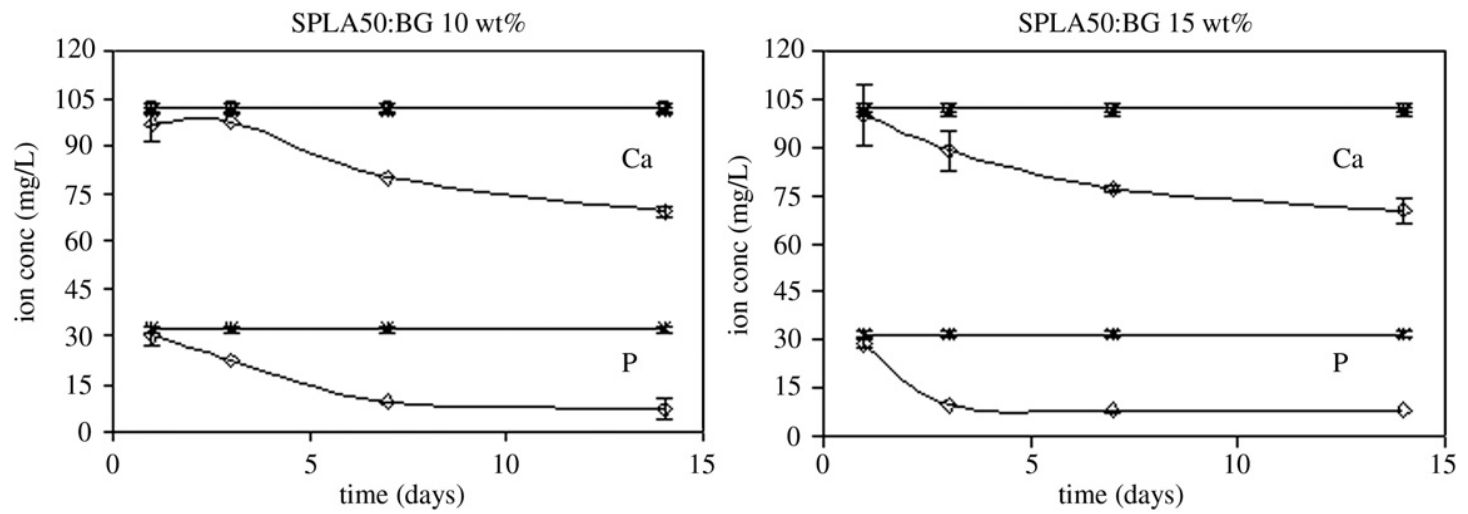

Fig. 8. Ion concentration ( $\mathrm{Ca}$ and P) in SBF solution as a function of immersion time for both matrixes SPLA50:BG 10 and 15 wt.\% (*control; $\boldsymbol{\square}$ SPLA50; $\diamond$ SPLA50:BG).

bioactive and present a bioinert behaviour when immersed in SBF solution.

The mechanism for the formation of bone-like apatite on polymeric surfaces was proposed by Kokubo et al. [34,35]. They suggest that the $\mathrm{CaO}-\mathrm{SiO}_{2}$ glass particles dispersed in the scaffold are used as a nucleation-inducing agent. According to this mechanism, silicate ions released from the glass particles are attached on the polymer surface and $\mathrm{Si}-\mathrm{OH}$ groups in the silicate ions induce the apatite nucleation on the surface. At the same time, the release of calcium ions from glass particles increases the ionic activity product of SBF with respect to apatite and accelerates the apatite nucleation. Finally, the apatite nuclei formed on the surface grow spontaneously by consuming $\mathrm{Ca}$ and $\mathrm{P}$ ions from the fluid.

\section{Conclusions}

In this work, a composite scaffold of Bioglass ${ }^{\circledR}$ and starch-based polymer with applications in tissue engineering was processed using the supercritical immersion precipitation technique. Supercritical fluid technology is a clean and environmentally friendly technology, capable of processing a wide range of materials in a single step process eliminating the need for further drying steps. This work demonstrated that biodegradable composites could be processed into porous structures using such methodology.

The in vitro bioactivity studies performed on the synthesized scaffolds have proven that the presence of Bioglass ${ }^{\circledR}$ can induce the formation of an apatite layer after 14 days of immersion. The conclusions taken from the morphological analysis are supported by the chemical analysis of the surfaces, namely by EDS, FTIR and XRD. Furthermore, the analysis of the SBF solution shows that the Ca and $\mathrm{P}$ ion concentrations are decreasing as the samples are immersed for longer periods of time, indicating that these ions are being consumed as the apatite layer is formed.

The preparation of impregnated scaffolds for tissue engineering purposes using supercritical assisted phase inversion could be adapted to prepare porous structures using other natural-based polymeric systems and a combination of different bioactive compounds.

\section{Acknowledgments}

Ana Rita C. Duarte is grateful for financial support from Fundação para a Ciência e Tecnologia through the grant SFRH/BPD/34994/2007. The authors also acknowledge the financial support from FCT through the project PTDC/QUI/69263/2006.

\section{References}

[1] X. Liu, P.X. Ma, Ann. Biomed Eng. 32 (3) (2004) 477.

[2] D.W. Hutmacher, J.T. Schantz, C.X.F. Lam, K.C. Tan, T.C. Lim, J. Tissue Eng. Regen. Med. 1 (2007) 245.

[3] J.F. Mano, G.A. Silva, H.S. Azevedo, P.B. Malafaya, R.A. Sousa, S.S. Silva, L.F. Boesel, J.M. Oliveira, T.C. Santos, A.P. Marques, N.M. Neves, R.L. Reis, J. R. Soc. Int. 4 (17) (2007) 999.

[4] J.M. Dang, K.W. Leong, Adv. Drug Deliv. Rev. 58 (2006) 487.

[5] P.B. Malafaya, G.A. Silva, R.L. Reis, Adv. Drug Deliv. Rev. 59 (4-5) (2007) 207.

[6] W.J.E.M. Habraken, J.G.C. Wolke, J.A. Jansen, Adv. Drug Deliv. Rev. 59 (4-5) (2007) 234.

[7] T. Guda, M. Appleford, S. Oh, J.L. Ong, Curr. Top. Med. Chem. 8 (4) (2008) 290.

[8] A.L. Oliveira, J.F. Mano, R.L. Reis, Curr. Opin. Solid State Mater. 7 (2003) 309.

[9] R.Z. LeGeros, Clin. Orthop. Relat. Res. 395 (2002) 81.

[10] M.V. Thomas, D.A. Puleo, M. Al-Sabbagh, J. Long-Term Eff. Med. Implants 15 (6) (2005) 585.

[11] Y. Abe1, T. Kokubo, T. Yamamuro, J. Mater. Sci., Mater. Med. 1 (4) (1990) 233.

[12] T. Kokubo, H. Takadama, Biomaterials. 27 (2006) 2907.

[13] T. Kokubo, Biomaterials. 12 (1991) 155-163.

[14] J.M. Oliveira, S.A. Costa, I.B. Leonor, P.B. Malafaya, J.F. Mano, R.L. Reis, J. Biomed. Mater. Res.: Part A 88A (2) (2009) 470

[15] G.A. Silva, F.J. Costa, O.P. Coutinho, S. Radin, P. Ducheyne, R.L. Reis, J. Biomed. Mater. Res.: Part A 70A (3) (2004) 442.

[16] S. Ghosh, J.C. Viana, R.L. Reis, J.F. Mano, Mater. Sci. Eng. C, Biomim. Supramol. Syst. 28 (1) (2008) 80

[17] J. Shi, L.H. Liu, X.M. Sun, S.K. Cao, J.F. Mano, Macromol. Biosci. 8 (3) (2008) 260.

[18] A.R.C. Duarte, J.F. Mano, R.L. Reis, J. Bioact. Compat. Polym. (in press).

[19] I. Kikic, P. Sist, in: E. Kiran, P.G. Debenedetti, C.J. Peters (Eds.), Supercritical Fluids: Fundamentals and Applications Proceedings of the 2nd NATO ASI on Supercritical Fluids; NATO Science Series, Kluwer, Dordrecht, Netherlands, 2000, p. 291.

[20] I Tsivintzelis, E. Pavlidou, C. Panayiotou, J. Supercrit. Fluids 40 (2007) 317.

[21] E. Reverchon, S. Cardea, E.S. Rappo, J. Membr. Sci. 273 (2006) 97.

[22] Y.W. Kho, D.S. Kalika, B.L. Knutson, Polymer 42 (2001) 6119.

[23] H. Matsuyama, A. Yamamoto, H. Yano, T. Maki, M. Teramoto, K. Mishima, K. Matsuyama, J. Membr. Sci. 194 (2001) 157.

[24] H. Matsuyama, A. Yamamoto, H. Yano, T. Maki, M. Teramoto, K. Mishima, K. Matsuyama, J. Membr. Sci. 204 (2002) 81.

[25] E. Reverchon, S. Cardea, J. Supercrit. Fluids 35 (2005) 140

[26] A.R.C. Duarte, J.F. Mano, R.L. Reis, Acta Biomater. (2009), doi:10.1016/j.actbio.2009.01.047.

[27] A.J. Salgado, O.P. Coutinho, R.L. Reis, J.E. Davies, J. Biomed. Mater. Res. part A 80 (4) (2007) 983.

[28] S. Ghosh, J.C. Viana, R.L. Reis, J.F. Mano, J. Mater. Sci., Mater. Med. 18 (2) (2007) 185

[29] S. Ghosh, J.C. Viana, R.L. Reis, J.F. Mano, Acta Biomater. 4 (4) (2008) 887.

[30] L.F. Boesel, J.F. Mano, C. Elvira, J. San Roman, R.L. Reis, in: E. Chiellini (Ed.), Biodegradable Polymers and Plastics, Kluwer Academic, Dordrecht, Netherlands, 2003.

[31] L.F. Boesel, J.F. Mano, R.L. Reis, J. Mater. Sci. Mater. Med. 15 (2004) 73.

[32] T. Kokubo, H. Kushitani, S. Sakka, T. Kitsugi, T. Yamamuro, Biomed. Mater. Res. 24 (1990) 721.

[33] C. Othsuki, T. Kokubo, T. Yamamuro, J. Non-Cryst. Solids 143 (1992) 84-92.

[34] P. Li, C. Otshuki, T. Kokubo, K. Nakanishi, N. Soga, T. Nakamura, T. Yamamuro, J. Am. Ceram. Soc. 75 (1992) 2094

[35] K. Rezwan, Q.Z. Chen, J.J. Blaker, AR. Boccaccini, Biomaterials 27 (2006) 3431. 